\title{
Unstable Generalized Transduction in Achromobacter
}

\author{
By D. R. WOODS AND JENNIFER A. THOMSON* \\ Department of Microbiology, Rhodes University, Grahamstown, South Africa
}

(Received 7 October 1974; revised 5 December 1974)

\begin{abstract}
SUMMARY
Six auxotrophic markers of a halotolerant collagenolytic strain of Achromobacter were transduced by four $\alpha$ phages. Abortive transduction was also demonstrated. The generalized transduction system is unusual as the transductants were unstable, characteristic of transduction by lysogeny. The Achromobacter strain is a cryptic lysogen for $\alpha$ and purified transductants were either sensitive or resistant to $\alpha$. Purified clones from four resistant transductants and one sensitive transductant liberated phage spontaneously. The host ranges of these spontaneous phages differed from that of the $\alpha$ phage used for the transduction experiment. Some initially resistant transductants became semi-sensitive to $\alpha$ (efficiency of plating [e.o.p.] IO $^{-1}$ to $\mathrm{IO}^{-2}$ ) after repeated cloning.
\end{abstract}

\section{INTRODUCTION}

Four closely related bacteriophages ( $\alpha$ phages) specific for halotolerant, collagenolytic strains of Achromobacter were isolated (Thomson \& Woods, 1974). Achromobacter strains become resistant to the $\alpha$ phages and do not adsorb phage when they are lysogenized by one of them. The strain, Achromobacter sp. 2, has been shown to be a cryptic lysogen for phage $\alpha_{3}$ and is not immune to superinfection by homologous phage. As the prophage can be induced with mutagens, it is proposed that the cryptic nature of the prophage is not due to an extensive phage deletion (Fischer-Fantuzzi \& Calef, 1964) but due to the mode of prophage integration and a defective excision mechanism (Krizsanovich, 1973; Thomson \& Woods, 1974). Since transduction is especially useful for the analysis of genetic fine structure and function (Hayes, I968), the transducing abilities of the $\alpha$ phages were tested with a view to developing a genetic mapping system in Achromobacter and studying the genetics of collagenase production.

Generalized transduction of a number of markers usually yields stable transductants by integration (Zinder, 1953) and specialized transduction of markers adjacent to the prophage attachment site yields unstable heterogenotes by lysogenization (Morse, Lederberg \& Lederberg, 1956). Specialized transducing particles can only be obtained by lysogen induction, while phage from lytic infection can perform generalized transduction (Zinder, 1955; Morse et al. 1956). Generalized transducing particles usually contain bacterial DNA synthesized before infection and little or no phage DNA (Ikeda \& Tomizawa, 1965; EbelTsipis, Botstein \& Fox, 1972). The formation of P22 transducing particles occurs independently of the known bacterial or phage recombination systems (Ebel-Tsipis, Fox \& Botstein, I972).

Generalized transducing phages have occasionally, however, been reported to yield heterogenote transductants (Luria, Adams \& Ting, 1960). Moreover, Chakrabarty \&

* Present address: Department of Microbiology and Molecular Genetics, Harvard Medical School, Boston, Massachusetts 02115 , U.S.A. 
Gunsalus (1969) showed that transduction of mandelate genes in Pseudomonas putida by phage pfi6h2 could yield stable or unstable transductants, depending on the degree of homology between incoming and recipient DNA as well as on the residual phage function in the transducing particles. Thus the distinction between generalized and specialized transduction may not always be clearly defined.

\section{METHODS}

Media. Nutrient broth (Difco) supplemented with $0.4 \mathrm{M}-\mathrm{NaCl}$ was used. For double-agarlayer phage assays, the media were as described previously (Thomson \& Woods, I973). Minimal medium was that of Grabow \& Smit (I967) supplemented with $0.4 \mathrm{M}-\mathrm{NaCl}$.

Bacteriophages. Four $\alpha$ phages (Thomson \& Woods, 1974) were used.

Isolation of mutants. Auxotrophic mutants of Achromobacter sp. 2 (Thomson, Woods \& Welton, 1972) were isolated by treatment of exponentially-growing broth cultures with $45 \mu \mathrm{g} N$-methyl- $N^{\prime}$-nitro- $N$-nitrosoguanidine (NTG) $/ \mathrm{ml}$ for $15 \mathrm{~min}$ at $37^{\circ} \mathrm{C}$. Six auxotrophs were isolated, $\arg , \operatorname{cys} A$ (temperature sensitive), $c y s B$ (non-temperature sensitive), met, pro and trp.

Phage techniques. Phage lysates were prepared according to the double-agar-layer method of Adams (1959), and the rapid loss of infectivity (Ioo-fold) after one week (Thomson \& Woods, 1974) was prevented by concentration and purification. Concentration was achieved by a two-phase system using Na-Dextran 500 (Pharmacia) and polyethylene glycol 6000 originally developed by Albertsson (1960). The concentrated phage was purified by caesium chloride density gradient centrifugation.

Transduction. Overnight broth cultures of auxotrophs were diluted I : 10 and aerated at $30{ }^{\circ} \mathrm{C}$ for $5 \mathrm{~h}\left(\mathrm{I} \times 10^{9} \mathrm{cells} / \mathrm{ml}\right)$. Two $\mathrm{ml}$ of culture were resuspended in $4 \mathrm{ml}$ phage lysate prepared on the wild-type strain at a multiplicity of infection (m.o.i.) of 1 to 5 , (where the m.o.i. is defined as per plaque-forming unit, (p.f.u.) adsorbed. The transduction mixture was incubated for $\mathrm{I} h$ for phage adsorption. Cells were harvested by centrifugation, resuspended in $0.4 \mathrm{M}-\mathrm{NaCl}$ and washed. The cells were added to minimal agar plates either by spreading or by means of a soft minimal agar overlay. Plates were scored for prototrophs after incubation at $30{ }^{\circ} \mathrm{C}$ for 2 to 4 days. Controls consisted of cells incubated with $4 \mathrm{ml} 0.4 \mathrm{M}-\mathrm{NaCl}$ and $4 \mathrm{ml}$ phage propagated on the homologous strain. Phage sterility was tested by spreading $0 . \mathrm{I} \mathrm{ml}$ on to salt and minimal agar. Control transduction experiments were also carried out using phage pre-incubated with antiphage serum $(k=10)$ for $15 \mathrm{~min}$.

Small transductant colonies. The small transductant colonies were streaked on to minimal agar and the isolated colonies assayed for cell counts on salt and minimal agar. The number of cells in these small colonies was compared with that of wild-type colonies on minimal agar.

Transductant stability. Transductants were streaked on to minimal agar before suspension in nutrient broth $\left(5 \times 10^{4}\right.$ cells $\left./ \mathrm{ml}\right)$ and incubated for $18 \mathrm{~h}$. Dilutions were plated on to salt and minimal agar and the rate of segregation per cell per generation calculated after incubation for $48 \mathrm{~h}$. The loss of trp by transductants was investigated by growth of the transductants in nutrient broth and nutrient broth containing ro $\mu \mathrm{g}$ acriflavine $/ \mathrm{ml}$. Dilutions were plated on to salt agar and I50 colonies from both acriflavine-treated and control cultures were tested for growth on minimal agar.

Phage characteristics of transductants. Twenty $\operatorname{Trp}^{+}$transductants obtained with an $\alpha_{3}$ a transducing lysate at a m.o.i. of I were purified by streaking on minimal agar (Ist cloning). Duplicate samples of three clones from each of these 20 streaks were restreaked on minimal agar (2nd cloning). The $\mathrm{I} 20$ clones were again purified by streaking twice more on minimal 


\section{Table I. Transduction by Achromobacter phages*}

Auxotrophic mutants of Achromobacter sp. 2 were used as the recipient strains at a m.o.i. of I to 5.

\begin{tabular}{|c|c|c|c|c|c|}
\hline Phage & Marker & $\begin{array}{c}\text { Io }^{-7} \times \text { Trans- } \\
\text { duction rate } / \\
\text { p.f.u. adsorbed }\end{array}$ & Phage & Marker & $\begin{array}{l}\text { Io }{ }^{-7} \times \text { Trans- } \\
\text { duction rate } / \\
\text { p.f.u. adsorbed }\end{array}$ \\
\hline \multirow[t]{6}{*}{$\alpha \mathrm{I}$} & arg & 0.13 & $\alpha 3 a$ & arg & $3 \cdot 3$ \\
\hline & $\operatorname{cys} A$ & 0.9 & & cys $A$ & $3 \cdot 2$ \\
\hline & $c y s B$ & I. 5 & & cys $B$ & $6 \cdot 5$ \\
\hline & met & $I \cdot 77$ & & met & $4 \cdot 3$ \\
\hline & pro & $I \cdot 6$ & & pro & $4 \cdot 8$ \\
\hline & $\operatorname{trp}$ & $\mathrm{I} \cdot 7$ & & $\operatorname{trp}$ & $7 \cdot 3$ \\
\hline \multirow[t]{6}{*}{$\alpha_{2}$} & arg & 0.0 & $\alpha_{3} b$ & $\arg$ & 3.5 \\
\hline & $\operatorname{cys} A$ & $3 \cdot I$ & & cys $A$ & $4 \cdot 6$ \\
\hline & cys $B$ & 0.0 & & cys $B$ & 6.0 \\
\hline & met & $I \cdot 85$ & & met & 4.0 \\
\hline & pro & 0.74 & & pro & 5.0 \\
\hline & trp & $2 \cdot 0$ & & $\operatorname{trp}$ & $7 \cdot 6$ \\
\hline
\end{tabular}

agar (3rd and 4th cloning). After each cycle of cloning, the strains were tested for sensitivity to phage $\alpha 3$ a by spotting high titres of phage (about $10^{8}$ p.f.u. $/ \mathrm{ml}$ ) on to double-agar-layer plates seeded with the transductants. Overnight broth cultures of the transductant clones were centrifuged, the supernatants sterilized with chloroform and tested for the presence of phage (spontaneous release) by spotting on to plates seeded with wild-type Achromobacter sp. 2. After the fourth cloning on minimal agar each strain was tested for induction of phage by u.v. irradiation. Cell samples were irradiated (Thomson \& Woods, 1974) and one ml portions were removed at different time intervals. The samples were pooled, phage broth was added, and the cultures incubated overnight before testing for phage.

Host range of spontaneously liberated phage. The spontaneously liberated phage and $\alpha 3 a$ were tested for infectivity on each of the I20 strains obtained after the fourth cycle of purification.

Isolation of double lysogens in complete and minimal medium. Ten colonies of wild-type Achromobacter sp. 2 were each suspended in complete and minimal broth and phage $\alpha 3$ a added. The cultures were incubated for 4 days and tested for sensitivity to phage $\alpha 3 a$ by spotting high titres of the phage on to double-agar-layer plates seeded with $0.1 \mathrm{ml}$ of the cultures. Clones isolated from the cultures by streaking were tested for induction of phage by u.v. irradiation.

\section{RESULTS}

Transduction. All four $\alpha$ phages were able to transduce the auxotrophs to prototrophy at a m.o.i. of I to 5 (Table I). Only those experiments where controls showed no growth were recorded. No transductants were formed when the transducing lysate was pre-treated with antiphage serum or when phage lysates propagated on the homologous strain were used.

When $\alpha 3 a$ was used to transduce the trp marker and the transductants were selected by spreading on to minimal agar, a transduction frequency of $7.3 \times 10^{-7} /$ p.f.u. adsorbed (Table I) was obtained. This low transduction frequency was increased to $\mathrm{I} \cdot 3 \times 10^{-6} / \mathrm{p}$.f.u. adsorbed by adding the cells to minimal agar by means of a soft minimal agar overlay.

Small transductant colonies. Apart from wild-type transductant colonies two types of small transductant colonies were observed. The first type were approximately a quarter of 


\section{Table 2. Phage characteristics of transductants obtained with an $\alpha_{3} a$ transducing lysate at a m.o.i. of $\mathrm{I}$}

Twenty transductants (Nos. I to 20) were streaked on to minimal agar and duplicate samples of three clones from each transductant were cloned a further three times on to minimal agar. Phage characteristics were determined after each cycle of cloning.

\begin{tabular}{|c|c|c|c|c|c|c|c|}
\hline Type & $\begin{array}{c}\text { All } 3 \text { clones } \\
\text { ex trans- } \\
\text { ductant } \\
\text { sensitive to } \\
\alpha_{3 a}\end{array}$ & $\begin{array}{l}\text { All } 3 \text { clones } \\
\text { ex trans- } \\
\text { ductant } \\
\text { resistant to } \\
\alpha_{3 a}\end{array}$ & $\begin{array}{c}\text { Two clones } \\
\text { ex trans- } \\
\text { ductant } \\
\text { sensitive } \\
\text { and one } \\
\text { resistant } \\
\text { to } \propto 3 \mathrm{a}\end{array}$ & $\begin{array}{l}\text { All } 3 \text { clones } \\
\text { ex trans- } \\
\text { ducant } \\
\text { initially } \\
\text { resistant } \\
\text { but at least } \\
\text { one clone } \\
\text { becoming } \\
\text { semi-sensi- } \\
\text { tive after } 3 \text { rd } \\
\text { or } 4 \text { th cloning }\end{array}$ & $\begin{array}{l}\text { Spontaneous } \\
\text { and erratic } \\
\text { phage } \\
\text { liberation } \\
\text { by one or } \\
\text { more of the } \\
\text { clones ex } \\
\text { transduc- } \\
g \text { tants* }\end{array}$ & $\begin{array}{l}\text { U.v. } \\
\text { induction } \\
\text { of phage }\end{array}$ & $\begin{array}{l}\text { Total no. of } \\
\text { transductants } \\
\text { and their } \\
\text { identification } \\
\text { numbers }\end{array}$ \\
\hline I & + & - & - & - & - & - & $4(I-4)$ \\
\hline 2 & - & + & - & - & - & - & $8(5-12)$ \\
\hline 3 & - & - & + & - & - & - & I (I3) \\
\hline 4 & - & - & - & + & - & - & $2(14, I 5)$ \\
\hline 5 & - & + & - & - & + & - & I (I6) \\
\hline 6 & - & - & + & - & $+t$ & - & I (I7) \\
\hline 7 & - & - & - & + & + & - & $2(18,19)$ \\
\hline 8 & + & - & - & - & + & + & I (20) \\
\hline
\end{tabular}

* Transductants went through a minimum of one cycle of cloning and growth in broth without phage release prior to spontaneous phage liberation.

$\dagger$ Phage liberation by resistant clone.

the size of the wild-type colonies. These small transductant colonies were obtained by both the spreading and overlay techniques and occurred most frequently when the transducing lysate used was at a m.o.i. of 50 to 100 . They were not abortive transductants as every cell in the colony could grow on both minimal and salt agar. The number of cells in a small colony on minimal agar was $2.4 \times 10^{5}$ compared with $6.0 \times 10^{8}$ in wild-type colonies on minimal agar. The colonies derived from the cells of the original small colony were likewise of the same small size.

The second type of small transductant colonies were abortive transductants. Abortive transduction was only obtained when the overlay plating technique was used.

Transductant stability. The average rate of segregation of trp $^{-}$in $\operatorname{Trp}^{+}$transductants when $\alpha_{3}$ a was used as the transducing lysate was $3.6 \times 10^{-3} /$ cell/generation. The other markers showed similar rates of segregation. The Trp ${ }^{+}$transductants were not cured by treatment with acriflavine. The segregation of $t r p^{-}$was not correlated with a change in phage characteristics.

Phage characteristics of transductants. The phage characteristics of twenty $\operatorname{Trp}^{+}$transductants (obtained with an $\alpha_{3}$ a lysate at a m.o.i. of I) which were purified by four cycles of cloning on minimal agar, could be divided into eight types (Table 2). Twelve of the transductants were either sensitive (type I) or resistant (type 2) to $\alpha_{3} \mathrm{a}$ and did not liberate phage spontaneously or after u.v. induction. Two of the transductant colonies gave rise to both sensitive and resistant strains (types 3 and 6). An interesting observation was the isolation of resistant and sensitive strains which showed spontaneous phage liberation (types 5, 6, 7 and 8). The transductant colonies (types 5,6 and 7) which showed resistance to phage $\alpha 3$ a gave rise to clones which released phage erratically but more frequently than the sensitive cryptic 
lysogen (Thomson \& Woods, 1974) which was used as the recipient. The sensitive transductant (type 8 ) continually released phage and was easily inducible by ageing and u.v. irradiation, in contrast to the parent cryptic lysogen which is only inducible by NTG (Thomson \& Woods, 1974). None of the resistant transductant clones were u.v. inducible.

Although the spontaneously liberated phage lysates and the induced lysate were tested for high frequency transduction (h.f.t.) of $t r p^{+}$, no h.f.t. preparations were detected.

Some of the transductant clones were initially resistant to $\alpha_{3}$ a but after three or four clonings became semi-sensitive (types 4 and 7). The e.o.p. of $\alpha 3$ a by these semi-sensitive colonies varied between $1 \mathrm{I}^{-1}$ and $1 \mathrm{I}^{-2}$. The decrease in e.o.p. was investigated to determine whether the phenomenon was due to restriction and modification. Plaques on a lawn of semi-sensitive cells were stabbed and the phage titre estimated on both the semi-sensitive strain and the wild-type bacterium. The semi-sensitive strain still showed the same reduction in e.o.p. as was obtained with the original $\alpha 3$ a suspension, indicating that $\alpha 3 a$ had not been modified by growth on the semi-sensitive strain.

Host range of spontaneously liberated phage. The host range of each of the five spontaneously liberated phages was greater and differed from that of $\alpha 3 a$. The spontaneously liberated phages were able to form plaques on the strains which were sensitive or semisensitive to $\alpha 3 a$ (Table 2) as well as on some strains which were resistant to $\alpha_{3}$. Each of the phages liberated after transduction was able to infect the respective transductants from which they originated. All the liberated phages infected the clones from transductants I 7 and I 4 which were resistant to $\alpha 3$ a. Furthermore, phage from transductants 16, I 7 and I 8 formed plaques on all the clones from transductants 10,15 and 16 . The phage from transductant 20 infected the clones from transductant 9.

Isolation of double lysogens in complete and minimal medium. The ten sensitive Achromobacter sp. 2 colonies, which were inoculated into complete broth containing phage $\alpha 3$ a, resulted in cultures which were resistant to $\alpha 3 a$. Clones isolated from these cultures were both resistant to $\alpha_{3} a$ and u.v. inducible, and were therefore double lysogens (Thomson \& Woods, 1974). These ten colonies were also inoculated into minimal broth containing $\alpha 3 a$ but formed cultures which were still sensitive to $\alpha_{3}$ a. No resistant colonies or u.v.-inducible double lysogens were isolated from the minimal-medium cultures.

Thomson \& Woods (1974) reported the isolation of double lysogens from colonies from the centre of turbid plaques on complete-medium double-agar-layer plates. In contrast, the plaques formed on Achromobacter sp. 2 by $\propto 3$ a on predominantly minimal-medium doubleagar-layer plates $(35 \mathrm{ml}$ minimal agar bottom layer with a $2.5 \mathrm{ml}$ soft complete-medium overlay) were completely clear, indicating that no resistant double lysogens had formed.

\section{DISCUSSION}

As the $\alpha$ phages all transduced a number of auxotrophic markers they were capable of generalized transduction. Generalized transductants are usually stable (Zinder, 1953) but Achromobacter transductants segregated auxotrophs. The transductants were not cured by treatment with acriflavine, suggesting that the transducing DNA did not remain as a plasmid in the recipient.

The range of phage characteristics and the spontaneous liberation of phage by purified transductant colonies is interesting, and was not due to either contamination by $\propto 3$ a or incomplete purification of the transductants. Four of the phages were liberated by strains resistant to $\alpha_{3}$. All the released phages showed a different host range from $\alpha 3 a$ and were able to infect some strains which were resistant to $\alpha_{3}$ a. The $\alpha_{3}$ a-sensitive strain which re- 
leased phage was inducible by u.v. and ageing. The transduction system involved a cryptic lysogen (Thomson \& Woods, I974) and a hypothesis is suggested to explain the range of phage characteristics of the transductants. It is envisaged that the generalized transducing particles contain bacterial DNA as well as different amounts of phage DNA. The cryptic lysogen is characterized by defective immunity and excision systems, and complementation between the resident cryptic prophage and phage genes on the transducing DNA could account for the range of phage characteristics of the transductants and the release of recombinant phage types. Luria et al. (I960) and Chakrabarty \& Gunsalus (1969) isolated transducing $P_{1}$ and pf 16 h2 particles containing varying amounts of phage genes.

None of the transductants showed the characteristics of normal double lysogens which are resistant to $\alpha$ and u.v. inducible (Thomson \& Woods, 1974). This suggests that only segments of the phage genome were available for complementation with the cryptic prophage and argues against the phage characteristics of the transductants being due to double lysogeny by contaminating non-transducing particles during transduction. Furthermore, double lysogens have only been isolated in complete medium, and attempts to demonstrate double lysogens in both liquid and agar minimal media were unsuccessful. This suggests that double lysogens cannot form in minimal media. The transductants were selected, purified and maintained on minimal medium.

As yet no h.f.t. lysates have been isolated. Watanabe, Ogata, Chan \& Botstein (1972) obtained only three h.f.t. lysates by u.v. induction of 26 independently isolated transductants. Therefore the screening of more transductants might result in the isolation of an h.f.t. lysate.

There have been reports of generalized transducing phages causing transduction either by integration or lysogenization. The choice depends on the degree of homology between the bacterial DNA in the transducing particles and the recipient strain, as well as on the amount of residual phage DNA in the transducing particles (Luria et al. 1960; Chakrabarty \& Gunsalus, 1969). However, although the phages worked with, PI and pr $16 \mathrm{~h} 2$, are capable of generalized transduction, DNA incorporation by lysogenization was in both cases shown only for a specific set of genes. With PI, lac and with pf I6h2, mandelate genes were transduced. Thus the $\alpha$ system is the first to show generalized transduction by a method other than the normal integration for a number of different markers.

D.R.W. acknowledges a Royal Norwegian Council for Scientific and Industrial Research fellowship and thanks Professor Helge Larsen, Biochemistry Department, Trondheim University for laboratory facilities. D.R.W. also acknowledges overseas bursaries from the Ernest Oppenheimer Memorial Trust and the South African C.S.I.R., and J.A.T. a Shell (S.A., Ltd) research fellowship.

\section{REFERENCES}

Adams, M. H. (1959). Bacteriophages. New York: Interscience Publishers.

Albertsson, P. (1960). Partition of Cell Particles and Macromolecules. New York: John Wiley \& Sons.

Chakrabarty, A. M. \& Gunsalus, I. C. (1969). Autonomous replication of a defective transducing phage in Pseudomonas putida. Virology $38,92-104$.

Ebel-Tsipis, J., Botstein, D. \& Fox, M. S. (1972). Generalized transduction by phage P22 in Salmonella typhimurium. I. Molecular origin of transducing DNA. Journal of Molecular Biology 7r, 433-448.

Ebel-Tsipis, J., Fox, M. S. \& Botstein, D. (1972). Generalized transduction by phage P22 in Salmonella typhimurium. II. Mechanism of integration of transducing DNA. Journal of Molecular Biology 7r, 449-470.

Fischer-Fantuzzi, L. \& Calef, E. (1964). A type of prophage unable to confer immunity. Virology $\mathbf{2 3}$, $209-21 \epsilon$. 
Grabow, W. O. K. \& Smit, J. A. (1967). Methionine synthesis in Proteus mirabilis. Journal of General Microbiology 46, 47-57.

HAYes, W. (1968). The Genetics of Bacteria and their Viruses. Oxford: Blackwell Scientific Publications.

IKEDA, H. \& ToMIZAWA, J. (1965). Transducing fragments in generalised transduction by phage PI. I. Molecular origin of the fragments. Journal of Molecular Biology 14, 85-98.

Krizsanovich, K. (1973). Cryptic lysogeny in Proteus mirabilis. Journal of General Virology 19, 3 I I-320.

LuRIA, S. E., Adams, J. N. \& TING, R. C. (1960). Transduction of lactose-utilizing ability among strains of $E$. coli and $S$. dysenteriae and the properties of the transducing phage particles. Virology 12, 348-390.

Morse, M. L., Lederberg, E. M. \& Lederberg, J. (1956). Transduction in K-I2. Genetics 4I, I42-1 56.

Thomson, J. A. \& Woods, D. R. (1973). Properties of a halotolerant Achromobacter strain and their infection with bacteriophage deoxyribonucleic acid. Journal of General Microbiology 74, 7I-76.

Thomson, J. A. \& Woods, D. R. (1974). Bacteriophages and cryptic lysogeny in Achromobacter. Journal of General Virology 22, I53-I 57.

Thomson, J. A., Woods, D. R. \& WeLton, R. L. (1972). Collagenolytic activity of aerobic halophiles from hides. Journal of General Microbiology 70, 315-319.

Watanabe, T., Ogata, Y., Chan, R. K. \& Botstein, D. (1972). Specialized transduction of tetracycline resistance by phage $\mathbf{P} 22$ in Salmonella typhimurium. I. Transduction of R factor 222 by phage $\mathbf{P} 22$. Virology 50, 874-882.

ZINDER, N. D. (1953). Infective heredity in bacteria. Cold Spring Harbor Symposia on Quantitative Biology I8, $261-269$.

ZINDER, N. D. (1955). Bacterial transduction. Journal of Cellular and Comparative Physiology 45, S2, 23-32. 